\title{
Kültür Merkezli Psikolojik Danışma: Kuramsal Bir İnceleme ${ }^{1}$ Gülşen BÜYÜKŞAHİN ÇEVIK ${ }^{2}$
}

Geliş Tarihi: 26.07.2013 Kabul Tarihi:12.12.2014

\section{$\ddot{\mathbf{O z}}$}

Bu makalede "Kültür Merkezli Psikolojik Danışma Yaklaşımı" ele alınmaktadır. Buna göre kültür merkezli psikolojik danışmanın amacı, temel kavramları, danışan ve kültürü, danışanın dünya görüşü, kültür merkezli psikolojik danışmada danışan-danışman ilişkisi ve psikolojik danışma becerileri ele alınarak önerilerde bulunulmuştur. Kültür merkezli psikolojik danışma yapanlar, bir yandan farklı kültürlerle ilgili bilgi sağlamanın yanında, toplumun bir üyesi olan insanları da kompleks olarak değerlendirmektedir. Buna bağlı olarak bu alanda çalışan psikolojik danışmanlar insanların dünya görüşlerine temel tutum, değer ve normlarını içinde bulunduğu toplum ve kültüre göre değerlendirmektedir.

Anahtar kelimeler: Kültür merkezli psikolojik danışma, çok kültürlü psikolojik danışma, kültür.

\footnotetext{
${ }^{1}$ Bu makalenin bir bölümü “X. Ulusal Psikolojik Danışma ve Rehberlik Kongresi’nde” sözlü bildiri olarak sunulmuştur. ${ }^{2}$ Yrd.Doç.Dr. Adıyaman Üniversitesi Eğitim Fakültesi, Rehberlik ve Psikolojik Danışmanlık Ana Bilim Dalı, gbcevik@adiyaman.edu.tr
} 


\title{
Culture Centered Counseling: A Theoretical Survey
}

Submited by 26.07.2013 Accepted by 12.12.2014

\begin{abstract}
Absract
Culture-Centered Counselling: A Theoretical Study- In this study Culture-Centered Counselling Approach were reviwed. According to this, Culture Centered approach' aims and basic concepts were studied. Also, client and cultur, approaching worldviews, dimension of worldview, client-counsellor relation and skills reviwed in Culture-Centered Counseling approach. Culture-Centered counsellors do not only mean gaining more knowledge of other cultures, but even more it means understanding the complex processes through which people become members of communities and societies and construct their worldviews, basic attitudes, values, norms.
\end{abstract}

Key words : Culture centered counselling, multicultural counselling, culture. 


\section{Giriș}

Dünyada kültürler birbirini etkilemektedir. Bundan dolayı insanoğlu bu etkileri anlamaya çalışmaktadır. Farklı profesyonel alanlar kültürlerin birbirini nasıl etkilediğini farkına varmaya çalışmaktadır. Özelliklede kültür merkezli psikolojik danışma alanı buna ihtiyaç duymaktadır. Kültür, aynı gelenek ve birikimi paylaşan insanların yeni nesillere aktardıkları bir grup öğrenilmiş davranışlar bütünüdür. Kültür bir toplumun bütün ideallerinin ve sosyal kişiliğinin bir sembolüdür. Kültürün iki temel fonksiyonu vardır. Bunlardan birisi koruyuculuk (muhafazakârlık) diğeri ise, gelişme ve yenilemedir. Bunlar iç içedir ve birbirini tamamlamaktadır (Erkal, 1997,s.132).

Kültürün bu fonksiyonlarını işlevsel hale getiremeyen toplumun üyesi olan bireyler çatışma yaşamaktadır. Bundan dolayı kültür merkezli psikolojik danışma alanında çalışan profesyoneller danışanın sahip olduğu kültürel farklılıkları öğrenerek, danışmaya yön vermesi ve yeterlilik geliştirmesi gerektiği belirtilmektedir (Sue, Arredondo ve McDavis, 1992). Bu yeterlilikler ise; a. Danışanın değerlerinin ve eğilimlerinin farkında olması, b. Danışanın farklı kültürel bakış açısını anlamaya çalışması ve c. Psikolojik danışmanın yeterli ve uygun psikolojik danışma becerisi ve tekniklerine sahip olması gerektiğidir. Bahsedilen her bir özellik psikolojik danışmanın şu üç boyutunu: a. İnanç ve tutumlarını, b. Bilgisini ve c. Becerilerini izlemektedir. Buna bağlı olarak psikolojik danışman danışanın farklı kültürel yapıdan ve geçmişten getirdiği kültürel yapılara bakarak kendisine bir yaklaşım belirlemesi gerektiğini vurgulanmaktadır. Buna göre; 1. Danışan ve danışman birlikte psikolojik danışmanın ortak amaç ve beklentilerini belirlemelidir. 2. Psikolojik danışman danışanın kültürüne uygun iletişim becerilerini kullanmalı ve geliştirmelidir. 3. Karşılıklı tutum ve beceriler geliştirilmelidir. 4. Danışanın çevre koşulları anlaşılarak danışma sürecinde izlenmelidir. 5. Evrensel ve kültürel özelliklere psikolojik danışmada dikkat edilmesi gerekmektedir (Launikari, Puukari, 2005, s.209). Kültür merkezli psikolojik danışma ülkemizde hem teorik hem de uygulamada yeni bir alan olduğundan bu çalışmanın bu alanda çalışan uzmanlara katkı sağlayacağı düşünülmektedir. Buna göre bu derleme çalışmada sırasıyla kültür merkezli psikolojik danışmanın amacı, temel kavramları, danışan ve kültürü, danışanın dünya görüşü, danışan-danışman ilişkisi ve kültür merkezli psikolojik danışmada psikolojik danışma becerileri ele alınarak önerilerde bulunulmuştur.

\section{Kültür Merkezli Psikolojik Danışmanın Amacı}


Rogers (1959; akt; Nelson-Jones, 2003, s.31) psikolojik danışmanın genel amacının, danışanın tam olarak fonksiyonda (olgun insan) bulunabilmesi için gerekli yardım süreci olarak nitelendirmektedir. Tam olarak fonksiyonda bulunan insanın özellikleri yaşantılara açık ve gerçekçi olarak algılayabilme, mantıklı olma, savunucu olmama, yaşamın varoluş süreçlerine bağlı olarak tanımlanmıştır. Öte yandan Dumont (1986, s.227) ve Taylor (1989, s.69) bireyin o toplumun hem bir parçası hem de farklı bir üyesi olduğunu belirtmektedir. Bu nedenle psikolojik danışmanın amacının gerçekleşmesi için danışanın kültürel yapısını ve temel yapılarını öğrenmenin önemi vurgulanmaktadır. Karşılıklı olarak danışan ile psikolojik danışman kültürel yapıları öğrenmek için birbirine yardımcı olmaktadır (Dumont, 1986; Taylor 1989). Öte yandan kültür merkezli psikolojik danışma birçok yaklaşımı kapsamaktadır. $\mathrm{Bu}$ nedenle danışanın probleminin tanımlanmasına göre danışmanın amacı oluşturulmaktadır. Genel olarak danışan hümanistik yaklaşımla ele alınmaktadır. Buna bağlı olarak danışanlar psikodinamik, davranışçı, hümanistik, gibi birçok yaklaşımla da ele alınmaktadır. Örneğin; kişinin kültürel olarak öğrendiği varsayımları psikodinamik bakış açısıyla değerlendirilirken, pekiştirilmiş davranışları davranışçı yaklaşıma göre ele alınmaktadır (Sue, Ivey ve Pederson, 1996, s.2). Buna göre kültür merkezli psikolojik danışmanın amacı, farklı kültürleri öğrenerek, bireylerin bağlı olduğu toplumları anlamaya çalışmak, bu toplumların içinde bulunduğu bireylerin dünyaya bakış açılarını, temel tutumlarını, değerlerini ve normlarını anlamaya çalışarak müdahale teknikleri geliştirmektir (Maruyuma 1992, s.35; Seeley 2000, s.59). Sonuç olarak kültür merkezli psikolojik danışma danışanın problemine göre birçok yaklaşımı içine alan bir yaklaşımdır. Psikolojik danışmanın genel amacı ise danışana etkili psikolojik danışma yapılabilmesi için öncelikle bireyin bağlı olduğu kültürün tanımlanması, kendisini ve dünyayı algılamasının çözümlenmesi gerektiği vurgulanmaktadir.

\section{Kültür Merkezli Psikolojik Danışmada Temel Kavramlar}

Kültür merkezli psikolojik danışmada, hem psikolojik danışman yeterliliklerini, hem de kültüre duyarlı danışman yeterliklerini ayırmadan ikisini de özümsenmesi gerektiği vurgulanmaktadır. Buna bağlı olarak psikolojik danışmanın insancıl bir tutumda olması, kendi kendinin farkında olması (self-awareness), kültürel farklılıklara duyarlı, kendi duygularını ifade edebilen, başkalarına model olma becerisi, özverili, etik ilkelere duyarlı, kendi ve danışanın becerileri hakkında sorumluluk duyan özelliklerde olması gerektiği ifade 
edilmektedir (Launikari ve Puukari, 2005, s.33). Buna karş1lık Sodowsky, Taffe, Gutkin ve Wise, (1994) kültür merkezli psikolojik danışman yeterliliğini şu şekilde ayırmaktadır: Çok kültürlü farkındalık, bilgi, beceri ve çok kültürlü danışman-danışan ilişkileri olarak ayırmaktadır. Psikolojik danışma ilişkisi genelde danışan ile psikolojik danışman arasında karş1lıklı bir etkileşimdir. Bu etkileşimde temel olan transferans ve konr-transferans kavramları ön plana çıkmaktadır. Bu kavramlar psikoanalitik teorilerde kullanılmakla birlikte, kültür merkezli psikolojik danışma açısından da önemlidir. Transferans çoğu zaman bilinçsizce danışanın başka insanlarla ilgili duygularını psikolojik danışmana taşımasıdır. Transferans yeni kültürel yapıya uyum sürecinde kendi kültürel yapısına uygun tepki ve duyguları ile ilişkilidir (Nelson-Jones, 2003, s.101). Buna karşılık Kontr-transferans psikolojik danışmanın geçmişteki önemli ilişkilerinden kaynaklanan tepkilerini danışana aktarmasıdır. Transferans ve kontr-transferans danışma ve terapi ilişkilerinde karşılaşılan (özellikle duygusal tepkilere) dinamikleri anlamaya yarayan kavramlardır (Launikari ve Puukari, 2005, s.34). Psikolojik danışmanın kendi değer yargılarını, inançlarını, sosyokültürel geçmişini, kuramsal yaklaşımını ve benimsediği kuramın kültüre duyarlılık açısından sınırlılıklarını iyi bilmesi gerekir. Psikolojik danışman kendisi ile ilgili farkındalığı sayesinde danışanların fenomolojik dünyasını çok daha iyi anlayabilir (Erdur-Baker, 2007). Psikolojik danışmanın kültürel yapısından kaynaklanan basmakalıp tutumlarının ve önyargılarının farkında olması önemlidir. Bu nedenle psikolojik danışmada şu iki sorunun cevabı önem taşımaktadır: a. Psikolojik danışman için danışan neyi ifade ediyor? b. Danışan için danışman neyi ifade ediyor? $\mathrm{Bu}$ iki sorunun cevabı psikolojik danışmanın devamlılığı açısından önem taşımaktadır (Launikari ve Puukari, 2005, s.34). Literatür incelendiğinde kültür merkezli psikolojik danışma açısından önemli olan bir başka kavramında empati ve saygının olduğu ortaya çıkmıştır. Gelso ve Carter (1985) empati ve saygının etkili psikolojik danışma yapmada kolaylık gösterdiğini açıklamışlardır. Çünkü empati danışanın öznel dünyasında bakabilmeyi gerektirmektedir, saygı ise danışanın olduğu gibi kabul edilmesini gerektirmektedir.

Kültür merkezli psikolojik danışmada önemli bir başka kavramda terapötik ilişkidir. Terapötik ilişki danışma ilişkisinde bilinçli bir şekilde işbirliğine dayalı, danışanın izni dâhilinde sorulan soru, karşılıklı hedeflerin olduğu, problem çözme ve geleceğe dair yolların bulunduğu psikolojik danışma sürecidir (Launikari ve Puukari, 2005, s.35). Bir başka açıdan Bordin (1975) çalışma işbirliğini (working alliance) üç boyuta dayandırmaktadır: a. Danışan 
ile psikolojik danışman arasındaki kurulan duygusal ilişki, b. Danışma için karşılıklı olarak belirlenmiş amaçlar ve c. Danışma yapısı üstünde yapılan anlaşmadır. Danışan ile psikolojik danışman arasında yapılan çalışma işbirliği (working alliance) farklı kültürel yapılardan gelen danışanlar psikolojik danışmanlar arasında fikir birliği oluşmasına neden olmaktadır. Çünkü danışan ve psikolojik danışman arasında iki eşit düzeyde bir terapötik ilişki vardır. Danışanın ihtiyacı bir otoriteden yaşamını düzenlemeye yönelik öğüt almak değil, psikolojik danışmanın yardımı yoluyla kendi gelişimi için kullanmaktır. Öte yandan danışanlar psikolojik danışma süreci hakkında yeterince bilgi sahibi olmayabilir. Bundan dolayı psikolojik danışman psikolojik danışma servislerinin çalışma biçimlerini, amaçlarını, nasıl yardımcı olabileceklerini, danışma prosedürünü, danışma yaklaşımı ve metotlarını açıklaması gerektiği vurgulanmıştır.

\section{Danışan ve Kültürü}

Her toplumun kendine özgü bir kültürü bulunmaktadır. Kültürel özellikler yalnız ülkeden ülkeye değişmemektedir. Aynı ülkenin kent ve köylerinde, hatta aynı kentin farklı mahallelerinde oturan insanların da kendine özgü kültürleri, gelenek ve görenekleri vardır (Baymur, 1994, s.274). Kültür merkezli psikolojik danışmada danışan içinde bulunduğu kültürden ayrı düşünülmemektedir. Danışanın hangi kültürden geldiği psikolojik danışmada önem kazanmaktadır. Danışanın hangi kültürden geldiğini anlamak için aşağıdaki özellikleri irdelemek gerekmektedir (Launikari ve Puukari, 2005, s.28). 1. Demografik değişkenleri (yaş, cinsiyet, oturduğu yer, vs.) 2. Statü değişkenleri (sosyal, eğitim, sosyo- ekonomik düzey, v.s) 3. Bağlı olduğu örgüt ya da kurumlar (formal ya da informal).

Yukarıdaki her bir özellik danışanın kültürü hakkında psikolojik danışmana bilgi vermektedir. Birey içinde bulunduğu toplumun değer yargılarını, davranışlarını, konuşma ve giyiniş biçimlerini benimseyerek o toplumun bir üyesi haline gelmektedir. Aynı zamanda evlenme, doğum, sünnet gibi merasimler, çocuk bakımı, eğlenme tarzları, atasözleri, batıl inançlar, eğitimli ya da eğitimsiz birçok bireyin kişilik özelliklerini etkilemektedir (Baymur, 1994, s.273). Aynı zamanda birey içinde bulunduğu kültürden etkilenerek, buna yönelik tutum geliştirebilmektedir. Kağıtçıbaşı (1999, s.124) kalıplaşmış tutumların, küçük yaşlarda başladığını, bu tutumların gelişiminde politik, tarihsel, ekonomik ve kültürel çeşitli etkenlerin rol oynadığını, başka insanlardan kulaktan dolma edinilen bilgilerle beslendiğini, gerçek bilgi eksikliğini giderme ve kişi için gerçeği tanımlama görevini gördüğünü vurgulamıştır. 
Öte yandan insan davranışlarının bilişsel, davranışsal ve çevresel faktörlerin karşılıklı etkileşimiyle açıklanabileceğine vurgu yapılmıştır. Diğer bir deyimle, davranış, çevre ve kişisel faktörler birbirini çok yönlü olarak etkilemektedir. Gündelik hayattaki öğrenmelerin büyük bir çoğunluğu sosyal öğrenmedir, yani kasttlı bir öğretim olsun veya olmasın, diğer insanlarla ilişki sonucunda gerçekleşmektedir. Konuşmayı, yemeyi, içmeyi, otobüse binmeyi, kahveye gitmeyi vb. başkalarını gözleyerek öğreniriz. Sosyal Öğrenme Kuramına göre, bireyler cinsel kimlik rollerini öncelikle anne babasını gözleyip taklit ederek öğrendiği belirtilmektedir (Bacanl1, 2005, s.41; Yeşilyaprak, 2003, s.204). Benzer olarak kültürün birey üzerindeki etkilerini incelediği araştırmada Abu-Rayya (2006) kültürel olarak farklı yapılardaki bireylerin psikolojik iyi olma, etnik ve ego kimliği arasındaki ilişkiyi incelemiştir. Araştırmanın bulgularına göre, Arap ve Avrupa etnik kimliklerinin etnik davranışlarla birleştiği, kabul, ait olma ve etnik grubun bir parçası olarak birlik duygusunun başarısı katılımcıların psikolojik iyi olma ile pozitif yönde ilişkili olduğu ortaya çıkmıştır

Öte yandan Bagley ve Copeland (1994) araştırmalarında 34 Afrikalı ve 48 AfroAmerikan kökenli üniversiteden mezun olmuş öğrenciler arasında kimlik ve problem çözme becerileri arasındaki farklı1ıkları incelemişlerdir. Araştırmanın sonuçlarına göre, problem çözme becerilerine göre gruplar arasında anlamlı farkl1lıklar görülmemiştir. Öte yandan Afrikalı öğrencilerin Amerikalı öğrencilere göre yeni bir çevreye uyum sağlama tecrübelerinin üç sene sürdüğü ortaya çıkmıştır. Benzer bir çalışmada Ramos-Sánchez ve Atkinson (2009) Amerika'da yaşayan Meksikalı yüksekokul öğrencilerinin yeni bir çevreye uyum sağlamasını, kültürel değerlerini, yardım etme amaçlarını incelenmiştir. Araştırmanın sonuçlarına göre, Meksikalı Amerikalıların kültürel kökenlerini kaybettikleri ve genel statülerini artırdıkları ortaya çıkmıştır. Ayrıca kültürel bir özellik olan yardım etme durumlarını daha az tercih ettikleri ortaya çıkmıştır. Sonuçta yapılan araştırmalara bakıldığında kültür ile birçok sosyo-psikolojik değiş̧en (evlenme, doğum, sünnet gibi merasimler, çocuk bakımı, eğlenme tarzları, atasözleri, batıl inançlar, kalıplaşmış tutumlar, politik ve tarihsel olaylar, vb.) arasında ilişki olduğu görülmektedir. Birey ile kültürü arasında karş̧1ıklı olarak bir etkileşim bulunmaktadır. Kültür merkezli psikolojik danışmada, psikolojik danışmanlar danışanların kültürüne ait edinilmiş inanç ve düşüncelerini göz önünde bulundurarak danışmaya yön verebileceği ve bu değisskenlere bağlı olarak müdahale teknik ya da programları geliştirilmesi gerektiği düşünülmektedir. 


\section{Danışanın Dünya Görüşü}

Kültür merkezli psikolojik danışmada yaşam ve yaşamın anlamı hakkında temel sorular önem taşımaktadır. "Gerçek” hakkındaki farklı düşünceler yaşam kavramı ile ilgilidir. Algımız bizi nasıl etkiler? Ben kimim? İnsanoğlu için bunun anlamı nedir? Yaşamın anlamı nedir? Ben nereye gidiyorum? Benim için diğer insanlar ne anlam taşımaktadır? Bütün bu sorular dünya görüşünün temel bir parçası olmaktadır. Danışan dünyaya kendi perspektifinden bakmaktadır. Bireyin dünyaya bakışı var olma, insanoğlu ve realite hakkında birçok varsayımı içermektedir. Aynı zamanda dünya görüşü kişiler arası ilişkileri ve doğa ile ilgili görüşlerini de kapsamaktadır (Launikari ve Puukari, 2005, s.104).

Öte yandan danışanın dünya görüşü kompleks olabilmektedir. Çünkü danışanın "gerçek" hakkındaki varsayımları kültürün kökenine bağlıdır. Psikolojik danışmanlar bir yandan danışana ait dünya görüşünün farkında olurken, diğer yandan kendi dünya görüşünün de farkında olarak danışanı bu konuda etkilememesi gerektiği belirtilmektedir (Arrendondo 1998; Burn, 1992; İbrahim, 1991; Jakson ve Meadow, 1991; Sue, Arrendondo ve Davis, 1992; Trevino, 1996). Psikolojik danışman, danışanın dünya görüşüne ait kültürel çatışmaları çözmeyi ve danışanın kültürel farklılıklarla baş edebilmesi için yardım etmeyi sağlamalıdır (Coleman, 1997). Danışanın dünyasını değerlendirmek için dünya görüşü hakkında pratik veriler elde edilmesi gerektiği ve elde edilen bu verilerin işlevsel olmasa da danışanı anlamamızı sağlayacağı vurgulanmıştır. Benzer olarak Sue, Arredondo ve McDavis (1992) danışanın dünya görüşünü öğrenmenin ve buna saygı duymanın psikolojik danışma sürecinde ilişki (raport) kurma açısından yararlı olacağını rapor etmektedir.

Buna karşılık dünya görüşünün değişik boyutları içerdiği belirtilmektedir. Dana’ya (1993) göre dünya görüşünün iki bileşeni bulunmaktadır: 1. Grup kimliği ve 2. Bireysel kimlik. Psikolojik danışmada bir insanın algıları bu boyutlardan etkilenmektedir. Benzer olarak Jackson ve Meadows (1991) dünyaya bakışın altını çizerek ve filozofik varsayımlardan yola çıkarak dünya görüşünü tartışmışlardır. Dünya görüşünün kültürel yapının derin bir parçasını temsil ettiğini ve bunun yanında kültürel faklılıkları anlamanın gerekli olduğunu vurgulamışlardır. Buna karşılık Deurzen-Smith (1988, s.127) farklı dünya görüş açılarını anlamamızda varoluşsal bir yaklaşım sunmaktadır. Bu varoluşsal yaklaşım, kişinin kişisel dünyaya bakış açısını yorumlamada bir harita sunmaktadır. Bu varoluşsal boyutların dört bileşeni kapsadığı belirtilmektedir. Bunlar Fiziksel (Milwelt), sosyal (Unwelt), kişisel (Eingenwelt) ve ideal (Überwelt) boyuttan oluşmaktadır. 
Hofstede (1991) tarafından yapılan araştırma sonucunda ise bireylerin dünya görüşünün oluşumunda sahip olduğu kültürün önemi vurgulanmaktadır. Araştırma sonucunda dört sentetik kültür (Alfa, Beta, Gama ve Delta) ortaya çıkmıştır. Alfa kültürü üyeleri arasında güç ve statü açısından eşitsizlik olduğu, bazı üyelerin diğerlerinden daha fazla firsat ve kaynaklara sahip olduğu, adalet ve eğitimde eşitsizliğin bu kültüre mensup üyeler arasında gerekli olarak görüldüğü, üstlerine bağımlılık hissettikleri ve dünya görüşlerinin de bu değişkenlerden etkilendiği bildirilmiştir. Öte yandan Beta kültüründe zamanın para olarak görüldüğü, iyi ya da kötü olan şeylerin kutuplaştırılarak kategorize edildiği, eğitim sisteminde bütün cevapların öğretmenlerden beklenildiği vurgulanmıştır. Buna karşılık Gama kültüründe yüksek bireyselcilik ve çekirdek aile yapısı ön planda olduğu, üyeler arasında gevşek bağların olduğu, kişisel zaman ve özgürlüğün gamalar için önemli olduğu ortaya çıkmıştır. Eğitim sisteminin amacı nasıl öğrenildiğini öğretmenin yanında, kişisel başarı ve becerileri öğretmek olarak ortaya çıkmıştır. Diğer yandan Delta kültürü erkeksi toplumlar olarak nitelendirilmiştir. Sosyal cinsiyet rolleri açıkça ayrıldığı, güce sempati duyulduğu, erkeklerin politikada, toplumda ve işyerlerinde belirleyici olduğu vurgulanmıştır. Kadınların ise, liderleri alkışlayan durumda olduğu belirtilmiştir. Delta üyeleri için okulda başarısız olmak felaket olarak görüldüğü, onlar için performans önemli olduğuna vurgu yapılmıştır.

\section{Kültür Merkezli Psikolojik Danışmada Danışan-Danışman İlişkisi}

Kültür merkezli psikolojik danışmada danışan-danışman ilişkisi bir yardım ilişkisidir. Psikolojik danışman danışanın kişisel hikayesini, problemlerini içeren hikayesini dinler. Burada şu sorular akla gelebilir: danışan kendini ne şekilde açıklayacak? Danışan bu ilişkide ne kadar dürüst olacak? Danışan psikolojik danışmanı bir memur, ya da bir kurumun temsilcisi olarak görebilir. Bu nedenle farklı kültürel yapılardan gelen bir bireyde bir ofis imajı ve sorulan sorular korku verebilir. Bu yüzden danışan dürüst davranmayabilir. Danışan dürüst olmadığı için problemleri de gerçek olmayabilir. Danışan işbirliğine hazır ve gönüllü olduğu zaman problemlerinin çözümü içinde bir adım atmış olmaktadır. Psikolojik danışman danışanı kompleks olarak göz önünde bulundurması gerektiği belirtilmektedir. Psikolojik danışmanın danışana ilk görüşmede soracağı sorular şunlar olabileceği belirtilmektedir: 1 . Psikolojik danışma hakkında ne biliyorsun? 2. Ben gerçekten seninle ilgilenir ve sorununu çözer miyim? 3. Psikolojik danışmandan ya da benden beklentin nedir? Bu sorular danışanın 
psikolojik danışma ve danışmanla ilgili bilgi sahibi olabilmesini de sağlamaktadır (Launikari ve Puukari, 2005, s.45-46).

Benzer olarak Amerikan Psikolojik Danışma Derneği'de (ACA, 1995) psikolojik danışmanlara kendi kültürel alt yapılarından farklı danışanlar konusunda bilgi sahibi olmaları ve farklılıklara duyarlı olmalarını vurgulamaktadır. Psikolojik danışmanların toplumdaki farklılıkları görmesi, her danışanın ayrı birey olduğunu ve kültürler arası bir yaklaşıma sahip olmaları gerektiğini belirtmektedir.

\section{Kültür Merkezli Psikolojik Danışmada Psikolojik Danışma Becerileri}

İlgili literatür incelendiğinde kültür merkezli psikolojik danışma açısından öncelikle psikolojik danışmanın planlanmasının önemli olduğu belirtilmiştir (Launikari ve Puukari, 2005, s.49). Kültür merkezli psikolojik danışma iyi bir planlamanın yanında objektif olabilmeyi de içermektedir. Ayrıca, psikolojik danışmanın görüşme stilini ve uygun bulduğu psikolojik danışma yaklaşımını gözden geçirmesine de ihtiyaç duymaktadır. Örneğin, daha resmi mi olmak gerekir? Konuşmanın rahatlatıcı mı olması gerekir? Yapılandırılmış uzun bir soru listesi ile görüşmenin yapılması mı gerekir? Ya da yapılandırılmamış mı olması gerekir? Kültür merkezli psikolojik danışmada tipik olarak beş aşamanın dikkate alınması gerektiği vurgulanmıştır (Pedersen ve Ivey, 1993, s.88) :1. Başlama: Bazı kültürlerdeki danışanlara ilk görüşmenin nasıl yapılacağı ile ilgili bilgi verilmesine ihtiyaç duyulabilir. Psikolojik danışman görüşmenin amacını belirterek, açık ve kapalı uçlu sorular kullanılarak görüşmeyi yapılandırır. 2. Dinleme: Psikolojik danışman danışanın problemini aktif dinleyerek daha sonraki görüşmeler için uygun müdahale yöntemlerini belirler. 3. Odaklanma: Danışanın problemine daha çok açıklık getirmesi, odaklanılması sağlanır. 4. Sonlandırma: Danışmada konuların gelişimi ve sonuçlandırılması psikolojik danışman tarafindan izlenir. 5. Kullanma: Görüşmede danışma ortamından öğrenilen şeylerin danışanların kendi amaçlarına uygun olarak yaşamında kullanması. Kültür merkezli psikolojik danışmada psikolojik danışmanın danışan merkezli yönlendirmeci yaklaşımları kullanması önemlidir. İyi bir görüşmenin yapılabilmesi için belirli durumlar için belirli iletişim becerilerini kullanma ve programlanmış cevaplar ya da kişisel beceri için standardize edilmiş kişisel becerinin ötesine geçmeye dayanmaktadır (Pedersen ve Ivey, 1993, s.89). Psikolojik danışmanın planlanmasının yanı sıra kültür merkezli psikolojik danışmada önemli olan temel becerilerde bu süreci etkileyen önemli faktörlerdendir. Bu beceriler: geribildirim becerileri, temel katılım becerileri, 
açıklama, özetleme cesaretlendirme becerileri, soru sorma becerileri, duygunun (feeling) ve içeriğin (meaning) yansittlmasl, yüzleştirme (confrontation) ve arabuluculuk (meditation) becerileri, odaklanma (focusing), yönlendirme (directing) ve yorumlama (interpreting) becerileridir. Bu becerilerin kültür merkezli psikolojik danışmanın gelişmesinde, yön vermesinde ve danışanın problemine müdahalede önemli beceriler olduğu düşünülmektedir. Aşağıda bu beceriler kültür merkezli psikolojik danışma açısından açıklanmıştır.

Geri Bildirim Becerileri (Feedback Skills): Kültür merkezli psikolojik danışmada geri bildirim becerileri önemli bir yer tutmaktadır. Uygun geri bildirim becerilerinin verilebilmesi için psikolojik danışmanın danışmayı yapılandırması gerekmektedir. Eğer geribildirim uygun bir şekilde verilmezse, etkileşim olumsuz sonuçlara neden olabileceği, psikolojik danışman tarafından gönderilen mesajın alınan mesajdan farklı olabileceği vurgulanmıştır. Bu nedenle geribildirimin danışan tarafından doğru algılandığından emin olunması gerektiği belirtilmektedir. Uygun bir geribildirimin için; 1. Psikolojik danışman danışanın kendisi ya da kişiliğinden ziyade davranışlarına odaklanmasının, 2. Psikolojik danışmanın anlam çıkarmadan çok gözlemlere odaklanması gerektiğinin, 3. Yargıdan çok tanımlamaya çalışmanın, 4. Şimdi ve burada ilkesine bağlı olmanın, alan ve zamandan uzak konu ve görüşmeler danışanın yaşamına katkı sunmayacağının, 5. Öğüt vermekten çok bilgi paylaşımına odaklanmanın, 6. Niçin söylediğinden çok ne söylediğine odaklanmanın önemine vurgu yapılmıştır. 7. Kullanılabilecek kadar bilgi vermenin, psikolojik danışmanın gereğinden fazla bilgi vermesi danışan tarafından özümsenmeyebileceği bildirilmiştir. 8 . Danışmanın kendisi için kullanışlı olmayan ve diğer insanlar için kullanışlı olan bilgiyi odaklanmasının önemli olduğu rapor edilmiştir (Pedersen ve Ivey, 1993, s.89). Uygun geribildirim vermek ise kültürden kültüre farklılaşmaktadır. Örneğin; maskülen toplumlarda fiziksel güce, para ya da maddi değerlere daha fazla önem verilebildiğinden, yarışmacı olabilecekleri vurgulanmıştır. Bu nedenle bu toplumlarda geribildirim verirken psikolojik danışmanın para, maddi değerleri, kültürel kahramanları, ya da yüksek statüdeki kişilerle ilgili bilgi sahibi olması gerektiği vurgulanmıştır. Öte yandan sosyal statü farklılıklarının belirgin olduğu toplumlarda ise geri bildirim becerileri kullanılırken, hiyerarşik gücün farkında olunması gerektiği, kibar, yumuşak bir ses tonuyla konuşulması, yardım etme sürecinde cesaretlendirmek gerektiği, resmi ve doğrudan göz kontağ kurmaktan sakınılması gerektiği vurgulanmıştır (Pedersen ve Ivey, 1993, s.90). 
Temel Katılım Becerileri (Basic Attending Skills): Katılım (attending) temel danışmanlık becerilerinden biridir. Seansta söylenilen ve olan şeylere dikkat etmek açısından önemli olduğu, sessiz ya da daha az konuşan danışanların cesaretlendirilmelerini sağladığı ve diğer bütün görüşme tekniklerine dayanılan bir temeli olduğu bildirilmiştir. Dikkatli gözlemde sözlü ve sözlü olmayan mesajların yorumlanmasına ve tanımlanmasını kolaylaştırdığı ve katılımın temel işlevinin ise danışanın problemi hakkında cesaretlendirmek olduğu belirtilmektedir. Bazı kültürlerde daha az sözlü iletişimin kullanıldığı, bu nedenle temel katılım becerilerinin danışanın değişmesi için uygun bir yaklaşım olduğu vurgulanmıştır. Danışmanın hoş görülü olması, danışanın sözlü ya da sözsüz, doğrudan ya da dolaylı kendini ifade etmesini yardımcı olmaktadır. Hem sözlü hem de sözlü olmayan iletişim danışanın eşit olarak psikolojik danışmaya katılması için önemli olduğu vurgulanmıştır (Pedersen ve Ivey, 1993, s.104).

Benzer olarak Ivey (1988, s.27) katılımı dört boyuta dayandırmaktadır. Birinci boyut gözlerin kullanılmasıdır. Bazı kültürler doğrudan gözlerle kontağa geçilmesini isterken, bazı kültürlerin ise bunu istemediği, bu nedenle danışmanın göz kontağı ile ilgili kültürel değerleri öğrenmesinin önemli olduğu rapor edilmiştir. Bütün kültürlerde gözler ilgi ve anlamın ifadesi olarak kullanılır. Danışanın göz kontağı ile ilgili kullandığı, tercih ettiği model danışman tarafindan model olarak alınması ve not alınması gerekir. İkinci boyut vücut dilinin kullanılmasıdır. Bu daha çok belirsiz ve yorumlanması zor olmasına karşın, genellikle çok önemlidir. Danışanın vücut diline dikkat etmek ve danışmanın iletişimini ve anlamını kusursuz bir şekilde olup olmadığı emin olmak için danışana sormak gerektiği vurgulanmıştır. Üçüncü boyut sesle ilgili niteliklerdir. Danışmanın ses tonu ve konuşması danışanın iletişimi ve duyguları üzerinde etkili olmaktadır. Psikolojik danışman ya da danışan yerel bir dil kullandığında bu özellik önem taşımaktadır. Dördüncü boyut sözlü takiptir. Psikolojik danışman danışan için gerekli bir söz takibinde kalması önemlidir, kafa karıştırıcı ve dolaylı olarak ifade etmek farklı kültürlerden gelen danışanlar açısından yanlış anlaşılmalara neden olabildiği belirtilmektedir.

\section{Açıklama (Paraphrasing), Özetleme (Summarizing) ve Cesaretlendirme (Encouraging)}

Becerileri: Kültür merkezli psikolojik danışmada açıklama, özetleme ve cesaretlendirme becerileri ile danışman danışanı psikolojik danışmada konuşulan konularla ilgili aktif olarak 
dinlediğini göstermektedir. Bu becerilerin danışanı görüşme sürecinde fikirlerini daha çok dile getirmeye istekli olmasını ve daha çok anlaşılmış hissetmesine yol açacağı rapor edilmiştir. Bu becerilerle konunun açıklığa kavuşması sağlanarak danışanın kendisini anlamasına yardımcı olmaktadır. Aynı zamanda bu beceriler danışma seanslarını azaltmasına yardımcı olarak daha etkili bir danışma süreci sağlamaktadır. Açıklama becerileri konunun amacına uygun söylenen şeyin özü hakkında danışmanın danışanın kendi kültürüne ait sözcükleri ile verilecek mesaja dair geri bildirim vermeyi içermektedir. Doğru açıklama güvenle yeni materyalin danışmana açıklanmasına izin vermektedir. Öte yandan sesin tonu ve vücut dili açıklamanın önemli bir parçasıdır. Psikolojik danışmanın açıklamayı doğru olarak yapması mesajın doğru olarak algılanması açısından önemlidir. Danışanın olaylar hakkındaki düşünce ve duyguları kültürel değerlerinin etkisini taşımaktadır. Bu nedenle danışanın kültürüne ait algılama ve yorumlamalarını psikolojik danışmanın bilmesi ve bu becerileri psikolojik danışmada kullanmayı gerektirecektir.

Buna karş1lık Özetleme becerileri açıklamalardan daha uzun ve daha çok bilgi içermektedir. Bu beceri genellikle görüşmenin başlangıcında ya da sonunda, zaman zaman psikolojik danışmanın konu değiştirmeye gerek duyduğunda geçişi sağlamak için kullandığ bir beceridir. Özetlemeler genellikle fazla zaman alır, hem sözlü ve hem de sözlü olmayan alınan ve verilen mesajları içermektedir. Örneğin, çoğu etnik grupta bir konudan bahsedilirken kendi kültürlerine ait temel bir hikaye ediliş biçimi vardır. $\mathrm{Bu}$ ifade ediliş biçimini danışanında danışma ilişkisinde ve iletişimde kullanacağı rapor edilmişstir. Bu hikaye ediliş biçiminin psikolojik danışman tarafından özetleme yapılırken danışanın kişisel hikayesinin kendi kültürüne özgü olarak hikaye edilmesi gerektiği vurgulanmaktadır. Buna karşılık Cesaretlendirme becerileri görüşmenin kesilmeden danışman tarafından yapılan baş sallamaları, açık elli mimikler, "um, hmmm", anahtar sözcüklerin tekrarı ya da görüşmede rahatlatma anlamı taşıyan diğer sözlü ve sözsüz içerikleri kapsamaktadır. Sessizlik bile cesaretlendirici olabilmektedir. Teşvik eden konu konuşmaya devam etmek için danışmanın cesaretlendirmesi ve mümkün olduğu kadar konuşmasının az kesilmesini içermektedir. Cesaretlendiricilerin aşırı derecede kullanılması ise gereğinden fazla danışanı zorlayabildiği rapor edilmiştir (Pedersen ve Ivey, 1998, s.117-119).

Soru Sorma Becerileri (Question-Asking Skills): Soru sorma becerileri ile psikolojik danışman açık ve kapalı uçlu sorular sorarak danışmada bilgi edinilmesine, danışanın uygun 
kararları alabilmesi ve görüşme hakkında spesifik detayları anlamasına yardımcı olmaktadır. Sanders (1966) psikolojik danışmanın basit temel sorulardan aşama aşama kompleks sorulara doğru bir yol izlemesi gerektiğini vurgulamaktadır. Öte yandan Ivey (1991, s.107) ise danışmanın danışan için beş farklı gelişim düzeyi sorusunun (başlangıç düzeyi soruları; duyumotor düzeyi soruları, somut işlemler düzeyi soruları, soyut işlem düzeyi soruları ve diyalektik-sistemik düzeyi soruları) olduğunu vurgulamıştır. Danışanın bilişsel gelişim düzeyine göre soruların sorulması gerektiği vurgulanmıştır. Danışanın gelişimine göre her bir soru farklı bir amaç gerektirebilir. Amacın gerçekleştirilmesinin ardından bir üst düzeyde soru sorulması gerektiği vurgulanmaktadır. Başlangıç düzeyi sorularında danışman danışanı problem için mümkün olduğunca cesaretlendirir, ardından özetleme ve açıklamalarda bulunur. Duyu-motor düzeyi sorulara geçildiğinde, danışman danışanın dünyaya bakışını anlamaya çalışır ve danışanın problemi danışanın duyusal, görsel algılarıyla somutlaştırılmaya devam edilmektedir. Böylece problemler tanımlanır. Duyu-motor düzeyi sorularıyla danışman danışanın olayları tanımlamasına yardımcı olarak durumu anlamasına yardımcı olmaktadır. Üçüncü düzey soruları olan somut işlemler düzeyi sorularında danışman olaylar ve duygular üzerinden daha az vurgu yaparak olayların gerçekçi bir zeminde birleştirilmesi için uygun sorular sormaktadır. Danışman danışanın problemden önce ve sonra ne olduğuna dair olayları tanımlamasını isteyerek problem hakkında danışanın düşünmesini kolaylaştıracak sorular sormaktadır. Ardından soyut işlem düzeyi sorulara geçildiğinde danışman yorumlama ve analize geçmeden önce danışanın olaylar hakkında tekrar konuşmasını sağlayacak sorular sormaktadır. Danışman danışanın problemi hakkında özet yapması için cesaretlendirilerek problemlerin içeriğinin daha kompleks olduğunun görmesi sağlanmaktadır. Beşinci düzey olan diyalektik/sistemik düzeyi sorularında danışman danışanın problemini bütün olaylarla birlikte bütünleyici olarak nasıl yapılandırdığını görmesini sağlamasına yardımcı olmaktadır. Danışman bu düzeyde danışanın problemi hakkında farklı bakış açılarına sahip olmasına yardım ederek çözüm için yollar bulunmasına yardım edilir. Ardından danışan çözümler için cesaretlendirilerek ve durumu kontrol için bir yapı denenmesine yardımcı olunur. Öte yandan Ellis ve Grieger (1977, s.37) Akılc1Duygusal Terapi’de sokratik tarzda soru sormayı önermektedir. Bu terapide de benzer olarak danışanın bilişsel düzeyine yakın sorular sorulmaktadır. Buna karşılık Rogers (1951, p.497) danışmanın olayları beyan eden soruları sorması gerektiğini vurgulamıştır. Öte yandan danışanın problem olan konu ile ilgili bilgi verebilmesi için kültürüne uygun sorular sormak 
gerekmektedir. Örneğin, psikolojik danışman, danışmada bireyselliğin önemsendiği toplumlarda başlangıç düzeyi soruları sorarken "bugünkü seansımızda size nasıl yardımcı olabilirim" şeklinde bir soru sorabilir. Buna karşılık hiyerarşik ve sosyal statü farklılıkların olduğu toplumlarda başlangıç düzeyi sorusu şu şekilde olabilmektedir: "bugünkü seansımızda ne konuşmak istersiniz?” şeklinde olabilmektedir. Farklı soru sorma biçimlerinin nedeni, danışanların farklı kültürel altyapılardan gelmeleri ve kültürel faktörlerin danışanların algıları ve kendilerini açma düzeyleri üzerinde etkili olduğu bildirilmektedir (Pedersen ve Ivey, 1998, s.133).

Duygunun (Feeling) ve İçeriğin (Meaning) Yansıtılması: Kültür merkezli psikolojik danışmada duygular yansıtılırken psikolojik danışmanın danışanın kompleks süreci ile ilgili duygularının açığa çıkarılması ve açıklık getirilmesine yardımcı olmaktadır. Psikolojik danışma sürecinde, psikolojik danışman danışanın duyguları hakkında geribildirim vererek psikolojik danışmaya odaklanılmasına ve konunun açığa kavuşturulmasına yardım etmektedir. Zaman zaman danışan duygularını birbirine karıştırır ya da ne hissettiğini anlayamamaktadır. Psikolojik danışmada duygular açığa çıkarılmazsa konu daha çok karmaşık hale gelerek çözümden uzaklaşılmaktadır. Özellikle de psikolojik danışman ve danışan farklı kültürlerde ise duygular ve problemler karıştırılabilmektedir. $\mathrm{Bu}$ nedenle zaman zaman danışmanın duyguları yansıtması gerekir, ardından danışana bu duygunun doğru olup olmadığı sorularak kontrol ettirilmesi gerekmektedir (Pedersen ve Ivey, 1998, s.149).

Öte yandan içerik yansıtmayla danışanın inançları ve değerlerinin keşfedilmesi amaçlanmaktadır. İçeriğin yansıtılması danışanın olayları doğru anlamasına ve yorumlamasına yardımcı olmaktadır. Böylece danışan amaçlarını keşfedebilir ve olayları daha derinden anlama firsatı yakalamaktadır. Kültür merkezli psikolojik danışmada içeriğin doğru yansıtılması belirli faktörlere bağlıdır. Bu faktörler danışanın kültürüne ait bilgi sahibi olma, bu kültüre ait duyguların farkında olunması ve buna bağlı olarak psikolojik danışmanın empati kurabilme becerisini içermektedir. $\mathrm{Bu}$ faktörler farklı kültürel yapıların açığa kavuşturulması ve tanımlanmasını sağlamakla mümkün olmaktadır. Psikolojik danışmanın içerik ve duyguyu yansıtabilmesi için empati kurması gerekmektedir. Empati ise danışanın psikolojik danışmada verdiği sözlü ve sözsüz mesajların psikolojik danışman tarafından doğru anlaşılmasına bağlıdır. İçerik ve duygu yansıtılırken konunun içeriğine 
odaklanılmasına, danışanın duygu ve davranışlarına benzer olmasına özen gösterilmesi gerektiği vurgulanmaktadır (Pederson, 1990).

Yüzleştirme (Confrontation) ve Arabuluculuk (Meditation) Becerileri: Her kültürdeki kurallar ve iletişim biçimleri birbirinden farklıdır. Yüzleştirme becerileri kullanılırken bu kural ve iletişim biçimleri tartışılarak yüzleştirme yapmak yararlı olabilmektedir. Öte yandan Ivey (1988, s.237) bir problemi çözmek için yeterince uyuşmazlığın olabileceğini vurgulamaktadır. $\mathrm{Bu}$ durumda danışanın çatışma ile yüzleştirilmesi gerekmektedir. Yüzleştirmenin özetleme, açıklama soru sorma, katılım, dinleme ve geribildirim becerileri birlikte kullanılabileceği belirtilmiştir. Ivey daha düşük bilişsel gelişim düzey basamaklarında çatışmanın daha çok yaşanabileceğini, bu durumu aşmak için yüzleştirme becerilerinin kullanılarak daha üst gelişimsel basamaklara geçilebileceğini ve bunun danışana işlevsellik kazandırabileceğini bildirmiştir. Öte yandan Goldstein ve Rosenbaum (1982, s.63) gerçek bir çatışmanın yapılandırılmış bir öğrenme ile davranışçı adımlarla beceri yapılandırmayı vurgulamışlardır. $\mathrm{Bu}$ şekilde danışanın model alma, tekrarlama, tartışma yoluyla birçok öğrenmenin gerçekleşebileceğini belirtmişlerdir. Cormier ve Cormier (1998, s.124) yüzleştirme becerilerinin danışana yeni çözüm ve alternatifleri keşfetmesine yardım etme yollarından biri olarak tanımlamışlarıdır. Ayrıca yüzleştirmenin uygun olmayan duygu ve düşüncenin farkına varılmasına yardımcı olduğunu vurgulanmıştır.

Kültürler arası psikolojik danışma açısından önemli bir başka beceri ise arabuluculuk becerileridir. Goldstein (1986) arabuluculuğu farklı kültürel gruplarda iki ya da daha fazla katılımcının bir konu hakkında görüşmesi olarak tanımlamıştır. Arabulucular ve tartışmacılar arasında farklı kültürel yapılar bulunabileceği, bu durumda kültüre özgü bir perspektife ihtiyaç duyulduğunu belirtmiştir. Bu ihtiyaç karşılandığında yaklaşımında başarılı olunabileceği savunulmuştur. Kültürler arası arabuluculuk kültürler arasında farklılık ve benzer ilişkileri içerir. Diğer yandan Janosik (1987) kültürler arası arabuluculuğu dört farklı yaklaşımla tanımlamıştır. 1. Danışanın kültürüne özgü davranışı yüzeysel olarak tanımlanarak basit bir analiz yapılır. 2. Gruplar arasındaki ilişkiler tanımlanarak grup içindeki yaklaşımı belirlenir. 3. Grubun içindeki farklılıklar ve dinamik eğilimler hakkında diyalektik olarak bilgi edinilerek kültür tanımlanır. 4. Bireyin kişiliğine etki eden kültürel değerler ve sosyal bağlama uygun bir yaklaşımla anlaşılmaya çalışılmaktadır. 


\section{Odaklanma (Focusing), Yönlendirme (Directing) ve Yorumlama (Interpreting)}

Becerileri: Kültür merkezli psikolojik danışmada odaklanma temel danışmanlık becerilerindendir. Danışanın yaşantısını kontrol eden kültürel olarak öğrenilen varsayımlara, kökleşmiş değerlere ve beklentilere odaklanılmaktadır. Bireyin kültürü merkeze alınarak bireyin sosyal sistem içerisinde öğrenilen davranış ve beklentileri mümkün olduğunca açıklığa kavuşturulmaktadır. Kültür kompleks ve dinamik olarak tanımlanmıştır. Yani her birey sahip olduğu kültürün içerisinde farklı sosyo-demografik özellikler, statü ve kuruluşlara üyeliklere sahip olmaktadır. Aynı zamanda bu yapı hem birey hem de kültür için sürekli değişmektedir. Bu nedenle psikolojik danışmanın danışanın öyküsünü sosyal sistemin içinde değișen yapı ve diğer kültürlerle arasındaki hareketliliğe bakmasına ihtiyacı vardır (Pedersen, 1990). Kültür merkezli psikolojik danışmada yönlendirme becerileri ise genellikle önerileri, tavsiyeleri ya da istekleri içermektedir. Danışman bir öğretmen gibi yeni bilgiyi danışana kavratır. Çoğu kültürde psikolojik danışma öğretme rolünü üstlenmektedir. Bu yolla danışman öğrettiği yöntemlerle etkili olmaktadır. Kültür merkezli psikolojik danışma açısından önemli olan bir başka beceride yorumlamadır. Danışman danışanın yorum yapabilmesi için uygun soruları sorar. Danışmanın danışmada yorum yapması danışanın yorumu kabul etmesine bağlıdır. Danışan bazen yapılan yoruma hazır olmayabilir, ya da yapılan yorum çok büyük değişiklik gerektirdiğinden danışan tarafından reddedilebilir. Danışanın kontrolünde yapılan yorumlamalar daha başarılı olabilir. Yorumlamalar danışanın gelişim düzeyine göre basit ve açık olması gerektiği vurgulanmaktadır. Aynı zamanda pozitif olarak yapılan yorumlamaların negatif yorumlamalardan daha çok değişiklik yarattığı belirtilmiştir. Yorumlamanın işlevi danışan için yeni bir perspektif sağlamaktadır. Kültür merkezli psikolojik danışmada yorumlama yapılırken danışman kültürel olarak farklı danışanın algılamalarının farkında olmasını gerekir. Yorumlamanın etkili olabilmesi için danışanın kültürüne uygun çeviri, ses tonu ve iletişim stili ile verilmesi gerekir (Ivey, 1988, s.56).

\section{Sonuç ve Öneriler}

$\mathrm{Bu}$ bölümde ilgili literatüre bağlı olarak önerilerde bulunulmuştur. Kültür merkezli psikolojik danışma alanında çalışacak uzmanların öncelikle danışanın kültürüne duyarlı olmaları gerektiği düşünülmektedir. Psikolojik danışma sürecinde, psikolojik danışman danışan ve kültürü hakkında bilgi edinerek elde ettiği veriler doğrultusunda psikolojik danışmaya yön verebilir. Kültür merkezli psikolojik danışma sürecinde temel kavramlardan 
(transferans, kontr-transferans, empati ve terapötik ilişki) yola çıkılarak danışmanın, danışmayı değerlendirmesi gerektiği düşünülmektedir. Özellikle psikolojik danışma sürecinde gelişebilecek transferans ve kontr-transferansa psikolojik danışmanın müdahale yöntemleri geliştirilmelidir. Kültür merkezli psikolojik danışma sürecinin sürekli bir öğrenme süreci olduğunu düşünerek, danışanın dünya görüşü, dünyayı yorumlayışı ve anlamlandırılış1 hakkında bilgi sağlayarak, problemin tanımlanması ve müdahale tekniklerinin geliştirilmesi gerekmektedir.

Öte yandan Bektaş (2006) kültür merkezli psikolojik danışmanın özellikle yardım hizmeti sunan meslekler için oldukça önemli ve yoğun bir şekilde tartışılan konuların başında geldiğini belirtmektedir. Uygulamalı psikoloji, psikiyatri, sosyal hizmetler, psikolojik danışma ve eğitim bu konunun önemini en çok vurgulayan alanlardandır. Aynı zamanda ülkemizde kültür merkezli psikolojik danışma yeni bir alan olduğundan literatürü henüz oluşturulamamıştır. Bu alandaki çalışmalar daha çok Amerikan literatürüne dayalı olarak takip edilmektedir. Dolayısıyla bu alanda Ülkemize özgü bir psikolojik danışma yaklaşımının oluşabilmesi için Türkiye'de yapılacak nitel ve nicel araştırmalara ihtiyaç duyulmaktadır. $\mathrm{Bu}$ araştırmalar ile kültürümüze özgü psikolojik danışma becerilerinin geliştirilmesine ihtiyaç duyulduğu düşünülmektedir. Buna karşılık Kağıtçıbaşı (1999)'da evrensel değerlerin, global sosyo-ekonomik gelişimin de Türkiye'deki kültür üzerinde önemli bir etkiye sahip olduğunu belirtmiştir. Yerel ve evrensel değerlerin birlikte bir uyum içinde olması gerektiğini ve kültürel değerlerin korunmasının önemli olduğunu, buna karşılık kültürel değişiminde kaçınılmaz olduğu, buna direnmenin toplumu ileriye değil, geriye götüreceğini rapor etmiş̧tir. Benzer olarak Erdur-Baker (2007) Türkiye'de yaşayan baskın ve alt grupları sözlü ya da sözsüz iletişim becerileri incelenerek psikolojik danışma sürecine yansıtılması gerektiğini bildirmiştir. Sonuç olarak kültür merkezli psikolojik danışma yaklaşımı danışanın kültürünü (cinsiyet, yaş, sosyo-ekonomik düzey, eğitim düzeyi, bağlı olduğu kurumlar, vb.) esas alarak uygun psikolojik danışma yaklaşımının ele alınması gerektiğini vurgu yapmaktadır. Buna bağlı olarak ülkemizde de kendi kültürümüze özgü kültür merkezli bir psikolojik danışma yaklaşımına ihtiyaç olduğu düşünülmektedir. 


\section{Kaynakça}

Abu-Rayya, H. M.( 2006). Ethnic identity, ego identity, and psychological well-being among mixed-ethnic Arab-European adolescents in Israel. British Journal of Developmental Psychology, 24, 669-679.

American Counseling Association. (1995). Code of ethics and standards of practice. Alexandria, VA:Author.

Arredondo, P. (1998). Integrating multicultural counseling competencies and universal helping conditions in culture specific contexts. Counseling Psychologist, 26 (4), 592601.

Bacanlı, H. (2005). Gelişim ve ögrenme. Ankara: Nobel Yayın.

Bagley, C.A. ve Copeland, E.J. (1994). African and African graduate students' racial identity and personal problem - solving strategies. Journal of Counseling, Development, 73, 669-679.

Baymur, F. (1994). Genel psikoloji. İnkılap Kitapevi: İstanbul.

Bektaş, Y. (2006). Kültüre duyarlı psikolojik danışma yeterlikleri ve psikolojik danışman eğitimindeki yeri. Ege Eğitim Dergisi , 7(1), 43-59.

Bordin, E. S. (1975). The generalizability of the psychoanalytic concept of the working alliance. Psychotherapy, Theory, Research, Practice, 16, 252-260.

Burn, D. (1992). Ethical implications in cross-cultural counseling and training. Journal of Counseling, Development, 70(5), 578-583.

Coleman, H.L.K. (1997). Conflict in multicultural counseling relationships: Source and resolution. Journal of Multicultural Counseling, Development, 25(3), 195200.

Cormier, W.H. ve Cormier, L.S. (1998). Interviewing strategies for Helpers. Pasific Grove, CA: Brooks Cole.

Dana, R.H. (1993). Multicultural assessment perspectives for professional

psychology. Boston: Allyn- Bacon.

Deurzen-Smith, E.V. (1988). Existential counselling in practice. London: Sage Publications.

Dumont, L. (1986). Essays on individualism. Chicago: University of Chicago Press.

Erdur-Baker, Ö. (2007). Psikolojik danışma ve kültürel faktörler. Türk Psikolojik Danışma ve Rehberlik Dergisi, 3(27), 109-119.

Ellis, A. ve Grieger, R. (1977). Handbook of rational-emotive therapy, vol.2. New. York: Springer.

Erkal, M.E. (1997). Sosyoloji. İstanbul: Der Yayınevi.

Gelso, C.J. ve Carter, J.A. (1985). The relationship in counseling and psychotherapy: Components, consequences, and theoretical antecedents. The Counseling Psychologist, 13, 155-243.

Goldstein, S. (1986). Cultural issues in mediation: A Literatur Review. P.C.R. Working Paper, University of Hawaii, Honolulu.

Goldstein, A ve Rosenbaum, A. (1982). Aggress-less: How to turn anger and aggression into positive action. Englewood Cliffs, NJ: Prentice-Hall.

Hofstede, G. (1991). Cultures and organizations: Software of the mind. London: McGraw Hill.

Ivey, A.E. (1988). Intentional interviewing and counseling: Facilitating client development. Pacific Grove, CA: Brooks Cole.

Ivey, A.E. (1991). Developmental strategies for helpers of individual, family and network interventions. Pacific Grove, CA: Brooks Cole. 
İbrahim, F.A. (1991). Contribution of cultural worldview to generic counseling and development. Journal of Counseling, Development, 70 (1), 13-19.

Jackson, A.P. ve Meadows, F.B. (1991). Getting to the bottom to understand the top. Journal of Counseling, Development, 70 (1), 72-76.

Janosik, R.J. (1987). Rethinking the culture-negotiation link. Negotiation Journal, October, 385-94.

Kağıtçıbaşı, Ç. (1999). Yeni insan ve insanlar. İstanbul: Evrim Yayınevi.

Launikari, M. ve Puukari, S. (2005). Multicultural guidance and counselling. Centre for International Mobility CIMO and Institute for Educational Research ISBN 95139 2121-2.

Maruyama, M. (1992). Context and complexity: Cultivating contextual understanding. New York: Springer-Verlag.

Nelson-Jones, R. (2003). Danışma psikolojisi kuramları. (Çev. Akkoyun, F.). $\quad$ Ankara: Nobel Yayın Dağıtım.

Pederson, P. (1990). The constructs of complexity and balance in multicultural counseling theory and practice. Journal of Counseling and Development 68,550-54.

Pedersen, P.B. ve Ivey, A. (1993). Culture centered counselling and interviewing skills. United States of America: An İmprint of Greenwood Publishing Group.

Ramos-Sanchez, L. ve Atkinson, D.R. (2009). The relationships between Mexican American acculturation, cultural values, gender, and help-seeking intentions. Journal of Counseling, Development, 87, 62-71.

Rogers, C. (1951). Client centered therapy. Boston: Houghton Mifflin.

Sanders, A.F. (1966). Expectancy: Application and measurement. Acta Psychologica, 25, 293-313.

Seeley, K.M. (2000). Cultural psychotherapy. Northvale, NJ: Jason Aronson.

Sodowsky, G.R., Taffe, R.C., Gutkin, T.B. ve Wise, S.L. (1994). Development of the multicultural counseling inventory: A self-report measure of multicultural competencies. Journal of Counseling Psychology, 41(2), 137-148.

Sue, D.W., Arredondo, P. ve McDavis, R. J. (1992). Multicultural counseling competencies and standards: A call to the profession. Journal of Counseling Development, 70(4), 477-484.

Sue, D.W., Ivey, A.E. ve Pedersen, P.B. (1996). A theory of multicultural counseling and therapy. California: Brooks/Cole Publishing Company.

Taylor, C. (1989). Sources of the self: The making of the modern identity. Cambridge, MA: Harvard University Press.

Trevino, J. G. (1996). Worldview and change in cross-cultural counseling. Counseling Psychologist, 24(2), 198-215.

Yeşilyaprak, B. (2003). Gelişim ve ögrenme psikolojisi. Ankara: Cantekin Matbaası. 